\title{
The National Library of Medicine Global Health Events web archive, coronavirus disease (COVID-19) pandemic collecting
}

\author{
Susan L. Speaker, PhD; Christie Moffatt, MSLS
}

See end of article for authors' affiliations.

\begin{abstract}
Since January 30, 2020, when the World Health Organization declared the SARS CoV-2 disease (COVID-19) to be a public health emergency of international concern, the National Library of Medicine's (NLM's) Web Collecting and Archiving Working Group has been collecting a broad range of web-based content about the emerging pandemic for preservation in an Internet archive. Like NLM's other Global Health Events web collections, this content will have enduring value as a multifaceted historical record for future study and understanding of this event. This article describes the scope of the COVID-19 project; some of the content captured from websites, blogs, and social media; collecting criteria and methods; and related COVID-19 collecting efforts by other groups. The growing collection-2,500 items as of June 30, 2020-chronicles the many facets of the pandemic: epidemiology; vaccine and drug research; disease control measures and resistance to them; effects of the pandemic on health care institutions and workers, education, commerce, and many aspects of social life; effects for especially vulnerable groups; role of health disparities in infection and mortality; and recognition of racism as a public health emergency.
\end{abstract}

\section{INTRODUCTION}

On January 30, 2020, as the World Health Organization (WHO) declared the novel severe acute respiratory syndrome coronavirus 2 (SARS-CoV-2) a public health emergency of international concern [1], the National Library of Medicine (NLM) began collecting web and social media documenting the emerging health crisis as part of its ongoing Global Health Events web archive collection (Figure 1) [2]. Web collecting is supported by the Collection Development Guidelines of the National Library of Medicine, which regard websites, blogs, social media, and other web content as increasingly important sources for documenting the scholarly biomedical record and illustrating diverse cultural perspectives in health and medicine [3]. Collecting and archiving content related to the coronavirus disease (COVID-19) pandemic follows earlier collecting efforts on the 2014 Ebola outbreak [4], the 2016 Zika virus outbreak [5], HIV/ AIDS [6], and the ongoing opioid epidemic [7]. This article describes the authors' collecting efforts relating to the coronavirus disease through June 2020.

As with NLM's earlier web collecting projects, its staff is collecting a broad range of born-digital web and social media resources to document the diversity of roles, experiences, and perspectives on the pandemic. Originally intended to share news and information about the pandemic as it happens, this content will have enduring value as a multifaceted historical record for future study and understanding of this event and its myriad effects on our lives. As we know, web and social media documents change frequently over time and can disappear completely without notice; therefore, NLM, along with many other libraries and archives, is working now, in real time, to identify, collect, and archive content to preserve it for future research.

\section{APPRAISAL AND SELECTION}

To build this collection following NLM's collection development guidelines, NLM's Web Collecting and Archiving Working Group - a team consisting of archivists, librarians, and a historian-is identifying web content around major public health events including "disaster management," "infectious diseases," "health communication," "history of medicine," and "popular literature" - in consultation with NLM's disaster health librarian 
and infectious disease subject matter expert. The working group is also seeking recommendations from across NLM and the Office of National Institutes of Health (NIH) History [8], and welcomes external suggestions through strategic communications, including a post shared in the History of Medicine Division's Circulating Now blog [9]. Through these efforts, the working group aims to document a variety of aspects of the pandemic, including research, facilities, support for and contributions of the health workforce, health disparities, social dimensions, personal narratives, ethical considerations, caregiving at home, the role and protection of nonmedical essential workers, efforts to count cases and track the disease, and rumors and misinformation.

Collecting material about this pandemic has been much more challenging than our previous NLM Global Health Events projects. More than observing from the sidelines, we are experiencing the event ourselves, as individuals - caring for loved ones, schooling children at home, and doing our part to slow the spread - and as staff in an institution actively involved in the response [10]. The coronavirus pandemic is a rapidly evolving and enormously disruptive worldwide event. Its effects extend far beyond the medical and public health sphere into every aspect of our lives: economic, political, social, cultural, and spiritual. Because the virus is new and can be fatal, all face a steep learning curve not only in clinics and research labs, but also in our everyday activities, which must be limited and reconfigured to constrain the spread of the virus. The pandemic is revealing both the strengths and the shortcomings of the world's various health care systems and of our scientific and public institutions. It has exposed longstanding racial and economic disparities and has likewise sharpened social and political fault lines.

The NLM Web Collecting and Archiving Working Group began by identifying the coronavirus websites of international, federal, state, and select local government and nongovernment organizations involved in the response, including the World Health Organization, US Centers for Disease Control and Prevention, NIH, all fifty-five states and territories, and Native American tribal governments. These websites document current status and updates on the spread of the coronavirus, health and safety information, and news of technological innovations, data sharing, and development of treatments and vaccines. Content includes resources for specific groups or individuals such as those who are deaf or hard of hearing, vulnerable populations such as those with underlying health conditions, or people experiencing homelessness, incarceration, or addiction, such as the US Centers for Disease Control and Prevention Resources to Support People Experiencing Homelessness (Figure 2).

Figure 1 National Library of Medicine Global Health Events web archive
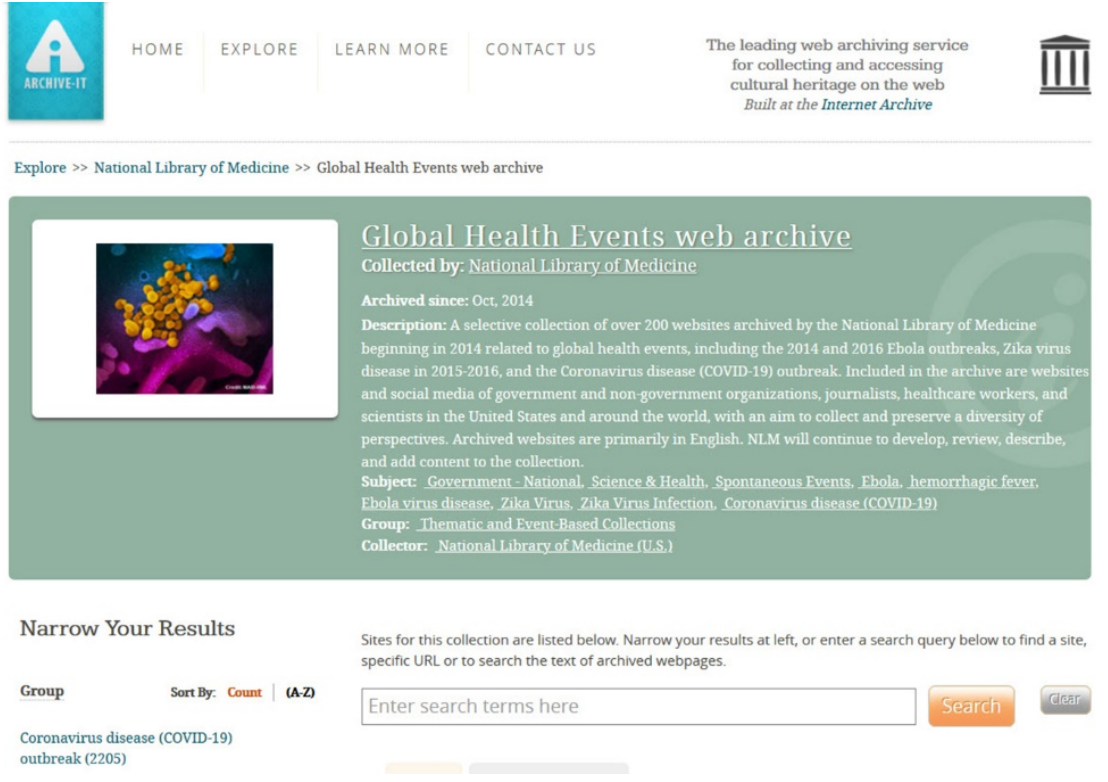

Sites for this collection are listed below. Narrow your results at left, or enter a search query below to find a site, specific URL or to search the text of archived webpages.

Enter search terms here

The Global Health Events web archive is available at $<\underline{\text { https://archive-it.org/collections/4887/> }}$. 
DOI: dx.doi.org/10.5195/jmla.2020.1090

Figure 2 Screen capture of US Centers for Disease Control and Prevention: Resources to Support People Experiencing Homelessness

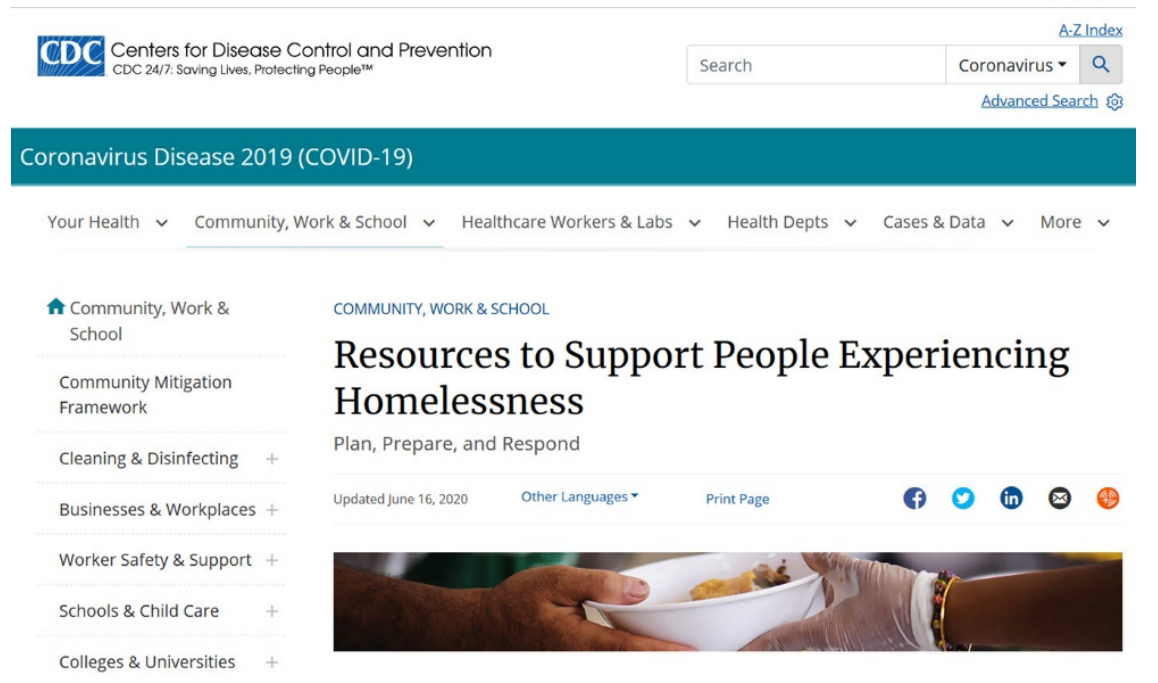

The archive of captures of the US Centers for Disease Control and Prevention Resources to Support People Experiencing Homelessness is available at <https://wayback.archive-it.org/4887/*/https://www.cdc.gov/coronavirus/2019-ncov/community/homeless-shelters/index.html>.

Along with government and health organizations, many other groups and individuals are contributing to the online coronavirus pandemic chronicle, providing myriad stories and perspectives. Our collection currently includes stories from nurses, physicians, and other health personnel at hospitals overwhelmed with COVID19 cases [11, 12]; patients who survived the disease [13]; and funeral home directors overwhelmed by high numbers of COVID-19 deaths. As the pandemic has evolved, the impact of longstanding health and economic disparities has become starkly clear, with African American, Hispanic, and Native American communities suffering disproportionate levels of COVID-19 infection and mortality [14]. This outcome has coincided with widespread protests addressing police brutality, which have yielded renewed efforts to recognize racism as a public health emergency and, more broadly, to appreciate social determinants of health in defining health disparities.

As it has dominated hospital facilities and required social distancing and quarantine, the pandemic has also done collateral damage to the "normal" health care landscape [15]. Reflecting this damage are the many stories and studies of what might happen when people delay treatment for heart attacks or strokes, for example, due to fears of COVID-19 in health care facilities, or when they delay routine vaccinations, surgery, and other care [16]. Mental health professionals are tracking increases in depression and anxiety and working to stay in touch with vulnerable patients. Also, those who depend on addiction treatment groups such as Alcoholics Anonymous have struggled to maintain support networks when it is not possible to meet in person.

Prevention strategies form another topical area in the coronavirus collecting effort. In the first months of the pandemic, we found many videos and other visuals about washing hands, sanitizing surfaces, and taking other preventive actions. Once it became clear that wearing face masks decreased the spread of virus-containing droplets, information about masks was soon all over the Internet: how to make them, how to wear them, and which ones are best [17-19]. Critical shortages of personal protective equipment (PPE) for health care workers, sanitizing supplies, and equipment such as ventilators hampered early efforts to care for COVID-19 patients and avoid spreading the disease. At the time of this writing, PPE shortages still constrain COVID-19 prevention and treatment in some parts of the United States [20,21]. These obstacles are another part of the pandemic story, including the ways that people have pitched in and helped to alleviate some of the shortages with innovations in manufacturing, repurposing, and alternative supply networks. Innovation, both practical and 
psychological, has also been required as people adapt to staying (and working) at home full time.

Resistance to and backlash against public health measures such as staying home and wearing masks in public places began within a month of the first stay-at-home orders in many states. The web content on this topic illustrates the essential, and in many cases historical, tensions present in large public health emergencies: between public health workers trying to inform the public, contain a dangerous disease, and save lives, and members of the public who see emergency restrictions (face coverings, testing, limiting public activities, and closures of public and private spaces) as infringements of individual freedoms and threats to their livelihoods. Related to these stories, we have also collected reports of preemptive resistance from vaccine opponents who fear that when a coronavirus vaccine is developed, the government will make it mandatory.

Just as web and social media furnish a rich fund of information about the pandemic's progress and all the varied responses to it, they also provide a wealth of misinformation and conspiracy theories. Because SARS-CoV-2 is new, there is a lot of room for rumor and misunderstanding about where it came from, how dangerous it is, who is most vulnerable, and what might prevent or cure it [22].

\section{SCOPING, DATA CAPTURE, AND QUALITY CONTROL}

We followed decisions about what content to capture with analysis and recommendations of how much of a site needs to be captured, how often, and for how long. The working group chooses to capture some materials only once, like a single blog post or news article; for others, the group decides to collect multiple copies over time (weekly, monthly, etc.) to document the evolution of content throughout the pandemic. We can see very specific changes such as the official naming of the virus in early February [23]; the WHO declaration on March 11, 2020, that COVID-19 had reached pandemic levels [24]; and broader changes in content and emphasis as organizations and individuals learn more about the coronavirus, how it spreads, and the varying impact on populations.

Monthly captures of the evolving $\mathrm{NIH}$ Coronavirus (COVID-19) website reveal a growing number of resources from March to June 2020, as $\mathrm{NIH}$ added news releases about research initiatives and clinical trials, NIH director blog posts, and information on NIH's Rapid Acceleration of Diagnostics (RADx) initiative and Accelerating COVID-19 Therapeutic Interventions and Vaccines (ACTIV) collaboration and data sharing efforts (Figure 3).

Figure 3 Screen captures of the National Institutes of Health (NIH) Coronavirus (COVID-19) website, March-June 2020
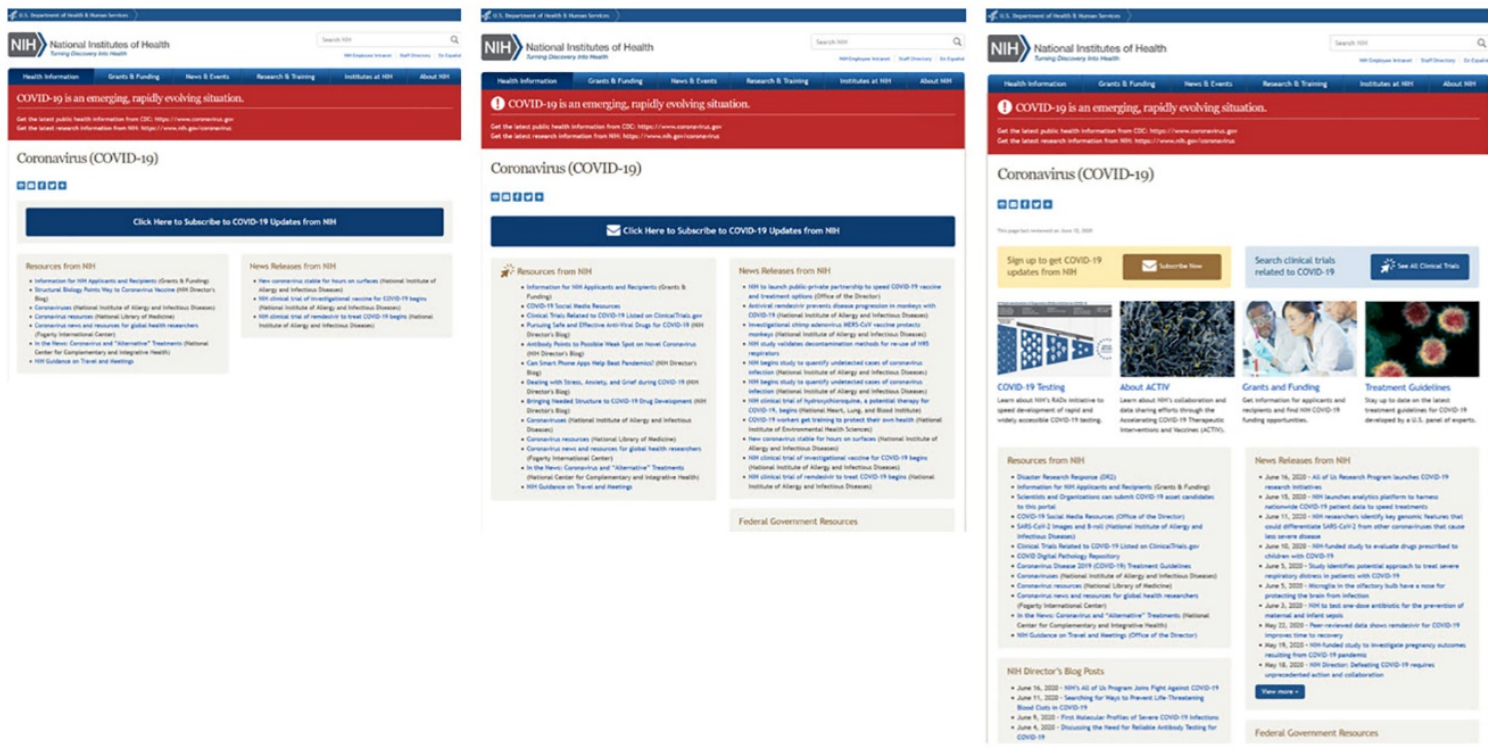

The archive of captures of the National Institutes of Health (NIH) coronavirus (COVID-19) website is available at <https://wayback.archiveit.org/4887/*/https://www.nih.gov/health-information/coronavirus>. 
The working group is mainly using the Internet Archive's "Archive-It" Service, which is a tool that allows libraries and archives to collect web content, preserve it in an archival format (WARC file), and make the saved content available to current and future researchers. While the Internet Archive is capturing a significant amount of content broadly across the web, NLM and many other libraries can use Archive-It to collect more deeply in specific areas of interest central to their mission. The working group is also experimenting with another tool called Conifer (formerly, Webrecorder) to collect more interactive and technically challenging content [25].

Following capture, the working group reviews collected content for quality, comparing the archived copy with the live version; adds metadata at the item and collection level to support discovery; notifies creators of the intention to include it in our collection if content is personal in nature; and provides access to the content through Archive-It's public user interface.

\section{RELATED COLLECTING EFFORTS}

While NLM's collection is mainly focused on the US experience, the working group is also contributing to a broader international collaborative effort to build a SARS CoV-2 outbreak web archive collection led by the International Internet Preservation Consortium [26, 27], with contributions from national and academic libraries around the world in over forty different languages. NLM is also engaged with other cultural heritage organizations that are archiving the history of COVID-19-in particular, the Society of American Archivists Web Archiving Roundtable, Archive-It community, National Digital Stewardship Alliance, and colleagues in the medical museum community - and is contributing to and following the growing list of institutions collecting COVID-19-related content that is maintained by the Documenting the Now project [28].

\section{CONCLUSION}

At the time of this writing, the NLM Web Collecting and Archiving Working Group's collecting effort includes nearly 2,500 sources, and COVID-19 is still an emerging, rapidly evolving situation. Resources, information, and documentation of experiences of the coronavirus - the primary resources of our time-are changing constantly, and new content continues to emerge. The scope of our collecting is evolving, too, as we learn more about the virus and its spread, who it affects most and why, and the long-term impacts. NLM's collection will, of course, only be a small sample of the tremendous amount of COVID-19-related content shared via the web and will complement the many other documentation efforts by libraries, archives, museums, and communities across the country and around the world to preserve web and non-web-based (e.g., diaries, journals) materials about the pandemic.

We also acknowledge that some perspectives will not be documented or shared for a wide range of reasons, including technical barriers, opportunity, or personal choice of the creators. The working group will continue to identify, collect, and archive content documenting the COVID-19 outbreak throughout the duration of the pandemic and the development and deployment of drug treatments and vaccines. We welcome recommendations (email, nlmwebcollecting@nlm.nih.gov) for content to include and new aspects to consider. We value the diversity of perspectives on what is valuable to document on this still-unfolding event so that our collaborative work today can yield the best possible future historical record for research and understanding.

\section{ACKNOWLEDGMENTS}

This work was carried out by staff of NLM, NIH, with support from NLM. The authors acknowledge and thank Delia Golden and Kristina Womack, NLM Technical Services Division; Sarah Eilers, John Rees, Ginny Roth, and Deshaun Williams, NLM History of Medicine Division; and Marielle Gage, Elizabeth Livesey, Brandon Wertz, and Erica Williams, History Associates Incorporated; Siobhan Champ-Blackwell, NLM Public Services Division; and Gabrielle Barr and Michele Lyons, Office of NIH History; and Ken Koyle, Jennifer Marill, Beth Mullen, Jeffrey S. Reznick, and Rebecca Warlow at NLM for leadership and support. The working group is also grateful for the many recommendations of content to include from within and outside of the NLM. 


\section{REFERENCES}

1. World Health Organization. Statement on the second meeting of the International Health Regulations (2005) Emergency Committee regarding the outbreak of novel coronavirus (2019-nCoV) [Internet]. The Organization; 30 Jan 2020 [cited 24 Jul 2020]. <https:/ / www.who.int/newsroom/detail/30-01-2020-statement-on-the-second-meetingof-the-international-health-regulations-(2005)-emergencycommittee-regarding-the-outbreak-of-novel-coronavirus(2019-ncov)>.

2. National Library of Medicine. Global health events web archive [Internet]. The Library [cited 24 Jul 2020]. $<$ https://archiveit.org/collections /4887? fc=websiteGroup \%3ACoronavirus + disease+\% 28COVID-19\%29+outbreak>.

3. National Library of Medicine. Collection development guidelines of the National Library of Medicine [Internet]. The Library [cited 24 Jul 2020].

<https://www.ncbi.nlm.nih.gov/books/NBK518732/>.

4. Moffatt C. Future historical collections: archiving the 2014 Ebola outbreak. Circulating Now [Internet]. National Library of Medicine; 9 Nov 2014 [cited 24 Jul 2020]. <https:/ / circulatingnow.nlm.nih.gov/2014/11/19/futurehistorical-collections-archiving-the-2014-ebola-outbreak/>.

5. Moffatt C. Web collecting during the Zika outbreak. Circulating Now [Internet]. National Library of Medicine; 28 Jun 2016 [cited 24 Jul 2020]. <https:// circulatingnow.nlm.nih.gov/2016/06/28/webcollecting-during-the-zika-outbreak/>

6. Wenc C. Archiving HIV/AIDS on the web. Circulating Now [Internet]. National Library of Medicine; 1 Dec 2017 [cited 24 Jul 2020]. <https://circulatingnow.nlm.nih.gov/2017/12/01/archivi ng-hiv-aids-on-the-web/>

7. Speaker SL, Moffatt $C$. The opioid epidemic: collecting now for future research. Circulating Now [Internet]. National Library of Medicine; 27 Sep 2018 [cited 24 Jul 2020]. $<$ https:/ / circulatingnow.nlm.nih.gov/2018/09/27/theopioid-epidemic-collecting-now-for-future-research/>.

8. National Institutes of Health. Office of NIH history \& Stetten Museum [Internet]. The Institutes [cited 24 Jul 2020]. $<$ https://history.nih.gov/>.

9. Moffatt C. Archiving web content on the coronavirus disease (COVID-19). Circulating Now [Internet]. National Library of Medicine; 26 Mar 2020 [cited 24 Jul 2020]. <https:/ / circulatingnow.nlm.nih.gov/2020/03/26/archivi ng-web-content-on-the-coronavirus-disease-covid-19/>.

10. Brennan P. Emergency funding allows NLM to expand COVID-19 research and services. Musings Mezzanine [Internet]. National Library of Medicine; 19 May 2020 [cited $24 \mathrm{Jul}$ 2020].

<https://nlmdirector.nlm.nih.gov/2020/05/19/emergen cy-funding-allows-nlm-to-expand-covid-19-research-andservices/>.

11. Thomas A. Annals graphic medicine - true tales from the outbreak: life in the hot zone. Ann Intern Med. 2020 May 5;172(9):W119-W120. DOI: http://dx.doi.org/10.7326/G20-0022.
12. Law T. Healthcare workers around the world are sharing bruised, exhausted selfies after hard days treating COVID19 patients. Time [Internet]. 22 Mar 2020 [cited 24 Jul 2020] <https://time.com/5807918/health-care-workers-selfiescoronavirus-covid-19/>.

13. Schneider E. My coronavirus story: a survivor shares her story [Internet]. 19 Mar 2020 [cited 24 Jul 2020]. <https:/ / www.youtube.com/watch?v=T7TGH2rO9-Y >.

14. Collins F. COVID-19 brings health disparities research to the forefront. NIH Director's Blog [Internet]. National Institutes of Health; 14 May 2020 [cited 24 Jul 2020]. <https://directorsblog.nih.gov/2020/05/14/covid-19brings-health-disparities-research-to-the-forefront/>.

15. Edelman S, Fitz-Gibbon J. EMTs have stopped taking people in cardiac arrest to coronavirus-strained hospitals. N Y Post [Internet]. 2 Apr 2020 [cited 24 Jul 2020]. <https://nypost.com/2020/04/02/ coronavirus-nycemts-stop-taking-cardiac-arrest-patients-to-hospitals/>.

16. Hughes T. 'It's horrible': hospitals cancel surgeries because of coronavirus, leaving Americans in pain. USA Today [Internet]. 1 Apr 2020 [update 2 Apr 2020; cited 24 Jul 2020]. <https://www.usatoday.com/story/news/nation/2020/0 4/01/coronavirus-surgery-cancellations-leave-thousandspain-over-delays/5094469002/>.

17. US Centers for Disease Control and Prevention. How to make masks: CDC on homemade cloth face coverings [Internet]. The Centers; 6 Jul 2020 [cited 24 Jul 2020]. <https://www.cdc.gov/coronavirus/2019-ncov/preventgetting-sick/how-to-make-cloth-face-covering.html>.

18. Parker-Pope T. How not to wear a face mask. N Y Times [Internet]. 8 Apr 2020 [cited 24 Jul 2020].

<https://www.nytimes.com/2020/04/08/well/live/coron avirus-face-mask-mistakes.html>.

19. US Centers for Disease Control and Prevention. Use of cloth face coverings to help slow the spread of COVID-19 [Internet]. The Centers; 28 Jun 2020 [cited 24 Jul 2020]. <https:/ / www.cdc.gov/ coronavirus/2019-ncov/preventgetting-sick/diy-cloth-face-coverings.html>.

20. US Centers for Disease Control and Prevention. Optimizing supply of PPE and other equipment during shortages [Internet]. The Centers; 16 Jul 2020 [cited 24 Jul 2020]. <https:/ / www.cdc.gov/ coronavirus/2019-ncov/hcp/ppestrategy/index.html>.

21. Parshley L. Remember the N95 mask shortage? it's still a problem. Vox [Internet]. 17 Jun 2020 [cited 24 Jul 2020]. <https://www.vox.com/2020/6/17/21293021/coronaviru s-n95-masks-prevent-covid-19-gloves-face-shields>.

22. Snopes Staff. The coronavirus collection: fact-checking COVID-19. Snopes [Internet]. 28 Feb 2020 [cited $24 \mathrm{Jul}$ 2020]. <https://www.snopes.com/collections/newcoronavirus-collection/>

23. Ghebreyesus TA. We now have a name for the disease caused by the novel coronavirus: COVID-19 [Internet]. Tedros Adhanom Ghebreyesus; 11 Feb 2020 [cited 21 Aug 2020]. <https://twitter.com/DrTedros/status/1227297754499764230>. 
24. World Health Organization. WHO director-general's opening remarks at the media briefing on COVID-19 [Internet]. The Organization; 11 Mar 2020 [cited 24 Jul 2020]. <https://www.who.int/dg/speeches/detail/whodirector-general-s-opening-remarks-at-the-media-briefingon-covid-19---11-march-2020>.

25. Conifer [Internet]. Conifer [cited 24 Jul 2020]. $<$ https://conifer.rhizome.org/>.

26. International Internet Preservation Consortium. Novel coronavirus (COVID-19) [Internet]. The Consortium [cited 24 Jul 2020]. <https://archive-it.org/collections/13529>.

27. International Internet Preservation Consortium. Netpreserve [Internet]. The Consortium [cited 24 Jul 2020]. $<$ https:// netpreserve.org/>.

28. Documenting the Now. Documenting COVID-19 [Internet]. Documenting the Now [cited 24 Jul 2020]. $<$ https:// docs.google.com/document/d/1v5tso8spFq6Sp W53h2OJULcdRoPEbyI6xpah31kW-H0/edit>.

\section{AUTHORS' AFFILIATIONS}

Susan L. Speaker, PhD, speakes1@nih.gov, Historian for the Digital Manuscripts Program, History of Medicine Division, National Library of Medicine, Bethesda, MD

Christie Moffatt, MSLS, christie.moffatt@nih.gov, Manager of the Digital Manuscripts Program, History of Medicine Division, and Chair, Web Collecting and Archiving Working Group, National Library of Medicine, Bethesda, MD

Received July 2020; accepted July 2020

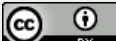

Articles in this journal are licensed under a Creative Commons Attribution 4.0 International License.

This journal is published by the University Library System of the University of Pittsburgh as part of its D-Scribe Digital Publishing Program and is cosponsored by the University of Pittsburgh Press. 